\title{
DIRETRIZES PARA A PREFEITURA DE FLORIANÓPOLIS - SC ATENDER A ESTRATÉGIA NA NACIONAL DE DISSEMINAÇÃO BIM
}

\author{
Késia Alves da Silva ${ }^{(1)}$, José Carlos Lino ${ }^{(2)}$, Rafael Fernandes ${ }^{(3)}$ \\ (1) kesia@alvesespindola.com, Alves e Espíndola Engenharia \\ (2) jclino@nossobim.com, NossoBIM \\ (3) rafael@flnbim.com.br, FLNBIM
}

\begin{abstract}
Resumo
A falta de diretrizes para as Prefeituras dos Estados brasileiros, em particular na Prefeitura de Florianópolis, para atender à estratégia nacional de disseminação do BIM (Building Information Modelling), causará grande impacto na implementação do plano estratégico, desenvolvido pelo Governo Federal, para essa disseminação. Esta estratégia busca incentivar o desenvolvimento do setor da construção, reduzir os gastos nas compras públicas, trazer maior transparência para os processos licitatórios e contribuir para a otimização de processos de manutenção e gerenciamento de ativos.

Desta forma, é de suma importância que uma estratégia local seja pensada e esteja alinhada com essa estratégia BIM BR, para que os resultados sejam sentidos nos estados e municípios, fazendo com que todos os projetos e obras sejam desenvolvidos em BIM.

O objetivo geral deste trabalho foi pesquisar diretrizes para que a Prefeitura possa atender à estratégia nacional de disseminação do BIM; redesenhando os processos atuais da Prefeitura, em especial, da Secretaria de Educação; verificando os principais pontos de mudança; sugerindo as principais metas a serem atingidas e desenvolvendo um cronograma de trabalho estratégico para a implementação do plano de metas consonante com a estratégia nacional de disseminação do BIM.

A metodologia utilizada foi a pesquisa aplicada, qualitativa, descritiva, com levantamento de dados, pesquisa bibliográfica, através dos métodos de procedimentos fenomenológico histórico, utilizando indexadores como Google Académico e Scielo, na busca por produções científicas tais como artigos científicos, dissertações, teses, normas técnicas e obras atualizados sobre o tema.

O estudo servirá de base para a Prefeitura Municipal de Florianópolis, órgãos públicos e, consequentemente, empresas privadas, nortearem as suas ações rumo à disseminação do BIM.
\end{abstract}

\section{Introdução}

O uso do BIM tem sido amplamente discutido e estudado no Brasil, com o objetivo de ser implementado nas obras públicas e privadas, para diminuir as inconsistências nos projetos, 
possibilitando assim obras com maior eficiência, menos desperdícios e redução de prazo, entre outros benefícios que a metodologia proporciona. As vantagens desta metodologia que, aos poucos, está a ser implementada na indústria da Arquitetura, Engenharia e Construção (AEC), ainda estão pouco exploradas. À medida que estas forem sendo absorvidas, causarão por certo grandes mudanças [1].

Esta metodologia é relativamente nova no Brasil, na área da construção civil, porém, o seu uso está já bastante avançado noutros países, tais como o Chile, o Reino Unido e a Finlândia, por exemplo, em que há a exigência de se contratar obras públicas com a premissa de que os projetos sejam desenvolvidos em BIM [2].

Com o objetivo de alinhar e buscar a eficiência das obras observadas nesses países, o governo Brasileiro instituiu alguns decretos. O decreto $\mathrm{n}^{\circ}$ 9.983, de 22 de agosto de 2019, revogou o decreto 9.377 de 22 de maio de 2018, mas confirmou o seu principal objetivo de decretar a disseminação da estratégia BIM BR [3].

Dessa forma, os órgãos públicos, estados e municípios, deverão definir estratégias para que suas metas estejam consonantes com as metas do plano estratégico BIM BR. Tratando especificamente do Município de Florianópolis e restringindo o olhar para a Secretaria Municipal de Educação (SME), percebe-se que é um grande desafio tal implementação para o município, pois são diversas unidades para se fazer a gestão de manutenção, contratação de projetos de reforma e também demandas de novas construções para atender à comunidade escolar. A estrutura da SME é extensa e complexa e existem muitas ações que precisam de ser pensadas para gerar um impacto positivo e assertivo rumo à adoção do BIM. O impacto nessa estrutura será grande, pois de acordo com a Estratégia BIM BR os principais projetos pilotos oriundos do governo federal, com o BIM como metodologia para a sua elaboração, já têm a data estimada de 2021 para início [4].

Dessa forma, entende-se que é de suma importância que sejam pensadas, entendidas e implementadas ações articuladas e estratégicas junto dos principais órgãos públicos federais, pois são eles quem proporcionará a adoção pelos estados, municípios e empresas privadas [4]. Nesse horizonte, a SME poderá utilizar elementos abordados neste estudo para planear as suas ações e assim definir diretrizes específicas para a sua realidade, mas que atendam a estratégia nacional de disseminação do BIM. A principal estratégia é consolidar o entendimento de que BIM não é software, mas uma metodologia que reúne processos, pessoas, software e gestão, tudo de forma colaborativa [1] e que com um plano bem estruturado levará a instituição ao sucesso na sua implementação.

\section{A Estratégia nacional de disseminação do BIM}

A crescente demanda de informação sobre o impacto do BIM noutros países, a consciência da sua adoção para melhoria na execução das obras públicas e privadas e motivados por uma série de ações de vários estados (Santa Catarina foi um dos pioneiros ao descrever políticas públicas, em 2014, através do Caderno de Apresentação de Projetos em BIM [5]), que contribuíram para uma política nacional que promovesse uma estratégia de disseminação.

No dia 7 de dezembro de 2016 foi assinado pelo Ministro Liam Fox (Reino Unido) e pelo Ministro Marcos Pereira (Brasil), no ministério da Indústria, comércio exterior e serviços do Brasil (MDIC), um Memorandum Of Understanding (MOU) que estabelece a cooperação para a implantação e disseminação do BIM no Brasil. A 6 de junho de 2017, foi assinado o decreto 
presidencial que criou o Comitê Estratégico de Implementação do BIM (CE BIM), que avaliou as demandas e iniciou estudos para avançar na adoção do BIM [9]. A 22 de maio de 2018 foi assinado o decreto 9.377 de que instituiu a estratégia BIM BR. Este decreto foi substituído pelo decreto $\mathrm{n}^{\circ}$ 9.983, de 22 de agosto de 2019, que instituiu o comitê para colocar em prática a estratégia BIM BR [3]. O Roadmap, que é parte integrante da estratégia BIM BR, elaborado pela equipe do comitê estratégico, apresenta as 8 estratégias e as ações a elas vinculadas, conforme apresentado na Erro! A origem da referência não foi encontrada..

\section{BIM BR Roadmap}

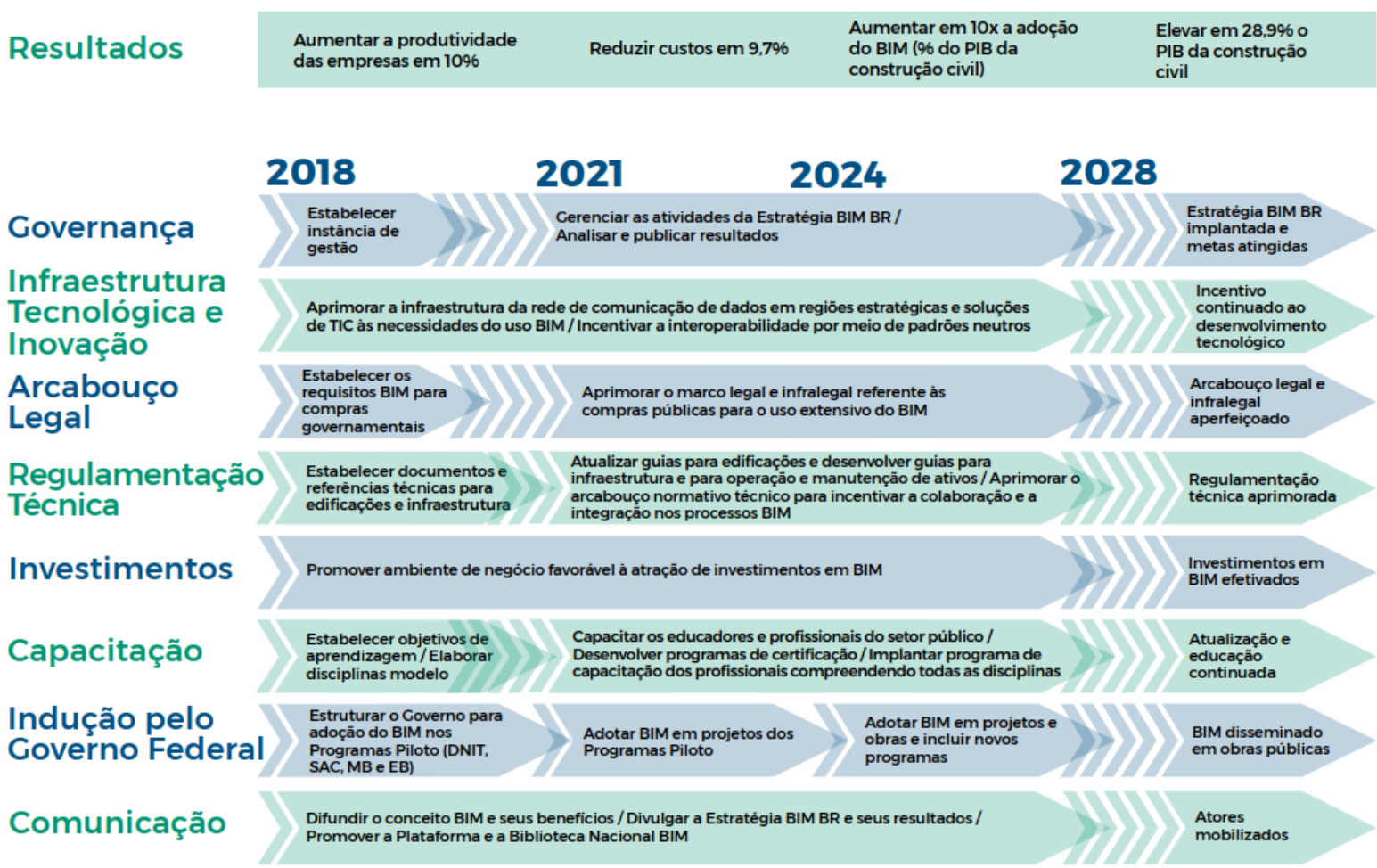

Figura 1: Roadmap da Estratégia BIM BR [4].

O ano de 2019 foi um ano bastante marcante para a história da implementação do BIM no Brasil. Foram organizados diversos eventos que deram a entender que a produção de projetos tem aumentado bem como o nível de conhecimento e, consequentemente, a adoção do BIM entre os engenheiros e arquitetos. Nota-se que muitos órgãos públicos federais estão em processo de implementação do BIM.

Outras importantes ações estão sendo desenvolvidas e amplamente divulgadas, sendo elas: a criação de uma norma Brasileiras referente a BIM ABNT ISO NBR 15965 - Sistema de classificação da informação da construção - partes 1 a 7 [6]; a criação de uma biblioteca nacional de objetos BIM; a criação de uma câmara de BIM nacional; a adoção da metodologia BIM em observatórios sociais e órgãos fiscalizadores; o aumento do uso de drones na extração de informações para modelos mais precisos; o aumento de oferta de software BIM e consequentemente a diminuição dos valores das licenças bem como a alteração na forma de comercialização de algumas dessas licenças, que são oferecidas em forma de locação; o grande 
aumento de conteúdo e cursos ofertados na internet referentes a BIM; a inclusão do ensino de BIM em diversas universidades; o crescente número de cursos de pós-graduação ofertando especialização em BIM; a grande quantidade de palestras abordando o tema BIM; a conclusão de obras que beneficiaram com o uso da metodologia BIM (apenas como exemplo a obra da Escola Básica da Tapera, obra em execução pela Prefeitura de Florianópolis, terá o seu prazo de conclusão diminuído e com zero de aditivo, graças à adoção da compatibilização dos projetos em BIM, da extração de quantitativos mais rigoroso e da melhoria do caderno de encargos [10]); o incentivo da adoção do BIM por Tribunais de contas, reafirmando o potencial do uso do BIM na fiscalização de obras públicas [11]; a publicação do Decreto no 10.306, de 2 de abril de 2020, que estabelece a utilização do Building Information Modelling na execução direta ou indireta de obras e serviços de engenharia realizada pelos órgãos e pelas entidades da administração pública federal, no âmbito da Estratégia Nacional de Disseminação do Building Information Modelling - Estratégia BIM BR [12]. Todas estas ações, entre várias outras, reforçam o movimento de adoção do BIM em diversas áreas no Brasil. Porém, este mesmo movimento não é percebido ainda em muitas prefeituras, que ainda se encontram na fase de entendimento da metodologia.

Percebe-se, em alguns casos, a compreensão equivocada de que BIM é um software e que a aquisição de licenças apenas substituindo um software anteriormente utilizado, os capacitará para utilizar plenamente a metodologia, o que provoca atraso no avanço do uso do BIM e muitas vezes até causa falta de estímulo. É preciso focar nos processos, que estarão envolvidos, nas pessoas e criar um plano de ação através de um grupo de trabalho, pois a realidade de implementação do BIM numa empresa privada e num órgão público é diferente em muitos aspetos. Eastman [1] entende que:

Um bom plano de implementação envolve a certeza de que a gerência (entre outros membroschave da equipe) adquiriu o completo entendimento de como o BIM pode dar suporte a processos de trabalhos específicos. Isso deveria ser feito em toda a companhia, ainda que qualquer empreendimento poderia ser usado como ponto de partida.

\section{A Prefeitura Municipal de Florianópolis}

Florianópolis é capital de Santa Catarina e possui cerca de 400 mil habitantes [7]. A estrutura organizacional da prefeitura, conta com equipe de engenharia nas diversas secretarias, sendo uma delas a SME. Esta gerência que possui mais de 120 unidades educativas, contrata obras e projetos e define padrões de especificações, entre outras diversas atribuições através da gerência de obras e manutenção predial (GOMP). A figura 2 ilustra os principais processos desenvolvidos no setor, em que, para cada etapa se detalha o fluxo das atividades dos setores que interagem com a GOMP. O município é referência pela qualidade da educação infantil e conta com diversas premiações e visibilidade nacional no tema. Possui uma creche pública com certificação Leadership in Energy and Environmental Design (LEED) Platinum e construiu uma escola utilizando a metodologia BIM reduzindo para metade o prazo de execução, sem nenhum aditivo [10]. 
ptBIM $2020-3^{\circ}$ Congresso Português de Building Information Modelling

26 e 27 de novembro e 4 de dezembro de 2020, Faculdade de Engenharia da Universidade do Porto

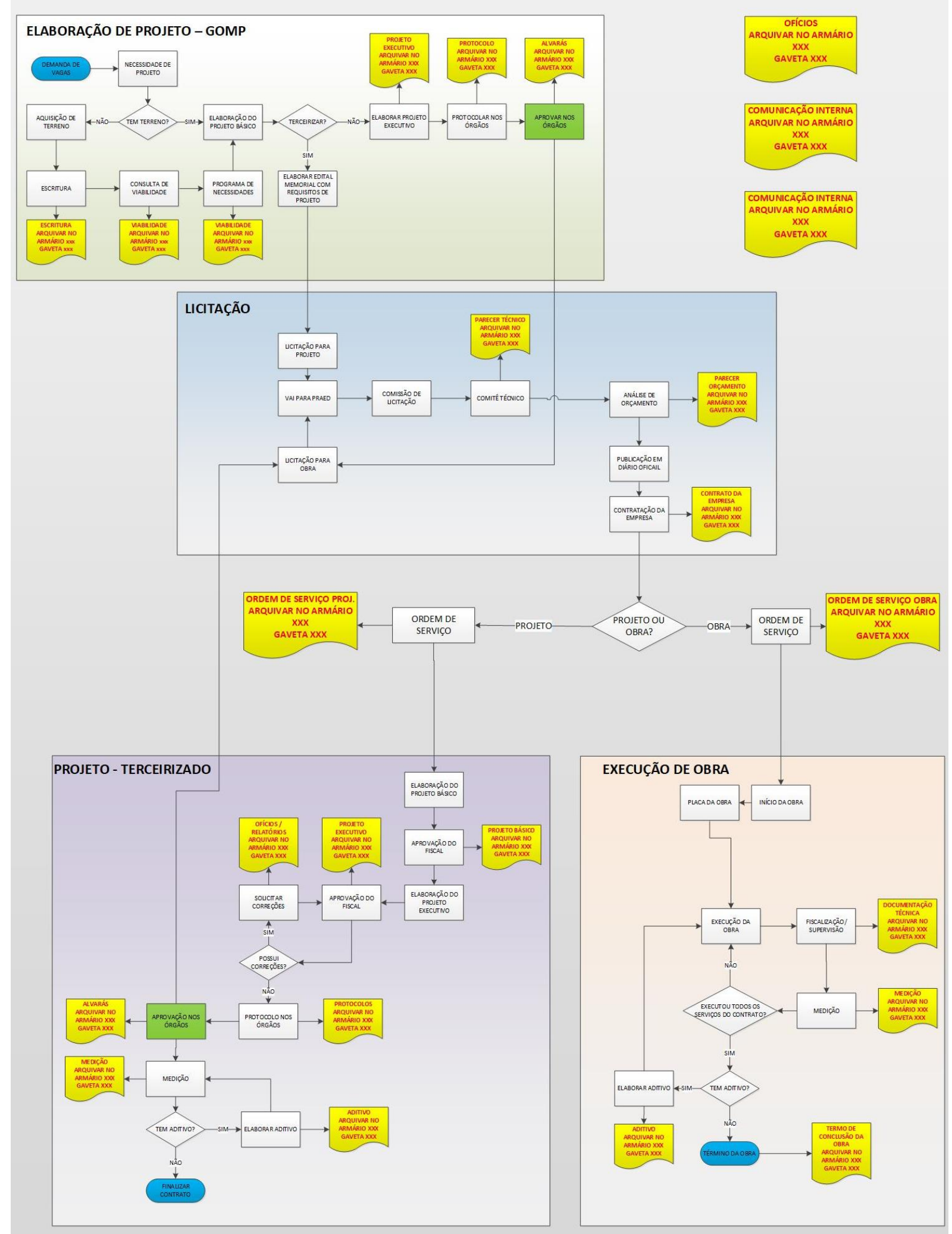

Figura 2: Fluxograma processos GOMP [8]. 


\section{Estratégia de implementação BIM para a prefeitura de Florianópolis}

Para alcançar o sucesso da implementação, é necessário analisar cada etapa, levantar pontos críticos e fazer um planeamento de ações adequadas às necessidades e à capacidade de ataque da equipe envolvida no processo. Para que tudo isso seja executado com maestria, é fundamental a definição de um coordenador, que preferencialmente seja um funcionário efetivo ou quando isso não for possível, que todos os processos sejam documentados de forma exaustiva, para que nada se perca e, em caso de saída do profissional da coordenação, o andamento das atividades não seja prejudicado.

Para nortear as ações desse coordenador, baseado na ideia de se implantar um processo, propõem-se as atividades, que seguem listam de seguida:

- Elaborar questionário de diagnóstico do nível de maturidade e gestão;

- Analisar os processos atuais da SME-GOMP, conforme Figura 2;

- Analisar processos digitais da SME;

- Analisar interações com outros planos;

- Mapear processos BIM e definir quais os usos que serão implementados;

- Analisar principais pontos de mudança;

- Desenhar novo organograma com a adoção do BIM;

- Desenhar novo fluxograma de processos com BIM;

- Criar o Grupo de trabalho BIM na secretaria municipal de educação (GTBIM-SME);

- Definir matriz de responsabilidades;

- Desenhar matriz de habilidades;

- Estabelecer metas:

As metas listadas abaixo refletem as principais necessidades de mudança encontradas através do questionário, elaborado no diagnóstico inicial.

- Meta 1 - Diminuir o retrabalho de projetos

- Meta 2 - Aumentar a digitalização da gestão de projetos

- Meta 3 - Capacitar os funcionários

- Meta 4 - Melhorar os prazos de execução de projetos

- Meta 5 - Melhorar a metodologia de elaboração de cronograma

- Meta 6 - Diminuir o percentual de aditivos por projetos

- Meta 7 - Contratar projetos em BIM

- Desenhar plano de ação;

- Elaborar cronograma de elaboração de documentos; Este cronograma elaborado pelo GTBIM-SME deve possuir no mínimo as seguintes ações:

- Diagnóstico inicial;

- Modelo de Contrato BIM;

- Modelo de BIM Execution Plan;

- Modelo de plano de necessidades;

- Dados de entrada de Projetos;

- Critérios de aceite de projeto (Checagem automatizada com regras);

- Edital de contratação para Projetos BIM;

- Critério de seleção das empresas licitantes; 
- Caderno de encargos;

- Diretrizes para elaboração de classes de objetos e parâmetros;

- Critérios de elaboração de cronograma;

- Critérios para elaboração de orçamento;

- Caderno de especificações técnicas da SME.

- Elaborar cronograma de capacitações internas;

O GETBIM-SME deverá definir um cronograma contendo no mínimo as seguintes ações:

- Datas das reuniões gerais;

- Datas das reuniões dos grupos de trabalho;

- Datas das reuniões de sensibilização;

- Datas das capacitações nos documentos e fluxo de processos;

- Datas das capacitações em software;

- Data do início do projeto piloto;

- Cronograma de elaboração geral de projetos.

- Elaborar cronograma de ações internas;

O GETBIM-SME deverá definir um cronograma contendo no mínimo as seguintes ações:

- Definir data para definição do(s) software(s) BIM utilizado(s);

- Definir data para a compra das licenças;

- Definir data de aquisição de hardware (se necessário).

- Elaborar cronograma de ações externas;

O GETBIM-SME deverá definir um cronograma contendo no mínimo as seguintes ações:

- Definir data da primeira contratação de projeto com requisito do uso do BIM;

- Definir capacitações externas (empresas de projeto e empresas de execução subcontratadas);

- Promover simpósios e palestras para o público em geral;

- Expor resultados para o público.

- Elaborar plano de comunicação e treinamento externo;

Caberá ao GTBIM-SME a criação de um plano de comunicação e de treinamento externo, com o objetivo de não excluir nenhum ator do processo, mas disponibilizar universalmente a informação, para que o processo seja melhor assimilado, desta forma, os resultados serão percebidos rapidamente;

- Comparar dados iniciais com metas desejadas.

\section{Florianópolis em 2024}

As metas que poderão ser alcançadas em 1 ano, após o início da implementação, conforme dados do questionário elaborado na abordagem inicial, são descritas na Tabela 1: 
Tabela 1: Comparativo: dados atuais $\times$ metas esperadas [8]

\begin{tabular}{lcc}
\hline METAS & Dado atual & $\begin{array}{c}\text { Metas } \\
\text { esperadas }\end{array}$ \\
\hline 1 - Percentual com retrabalho em projetos & $100 \%$ & $-50 \%$ \\
2 - Percentual de Gestão digital das informações dos projetos & $0 \%$ & $80 \%$ \\
3 - Percentual de profissionais técnicos capacitados em BIM & $0 \%$ & $50 \%$ \\
4- Percentual de Projetos que atendem ao prazo contratual & $0 \%$ & $80 \%$ \\
5 - Percentual de projetos que possuem cronograma vinculado & $0 \%$ & $50 \%$ \\
ao modelo & $100 \%$ & $<10 \%$ \\
6- Percentual de aditivo de projeto & $0 \%$ & $80 \%$ \\
7 - Percentual de empresas de projetos utilizando BIM &
\end{tabular}

Novas metas poderão ser incluídas a critério do gestor ou das demandas que começarem a ser identificadas com essa nova gestão de dados.

Além dessas metas, acredita-se que num horizonte de 2 a 4 anos Florianópolis possa:

- Expandir a adoção do BIM para outras secretarias;

- Aprovar projetos utilizando a análise de arquivos que utilizem formato de dados que permitir o intercâmbio de um modelo informativo sem perda ou distorção de dados ou informação, conhecido como Industry Foundation Classes (IFC);

- Contratar todos os projetos e obras em BIM;

- Possuir um ambiente comum de dados e fazer gestão digital das informações;

- Utilizar cadastro multiuso para gestão de seus ativos, com interface com BIM;

- Integrar $100 \%$ o processo de licitação ao modelo virtual e ao cadastro de insumos;

- Possuir um mapeamento de todo território em software BIM/CIM/SIG e disponibilizar ao cidadão para consulta de viabilidade;

- Fazer gestão dos recursos hídricos, viários e de planeamento urbano utilizando softwares $\mathrm{BIM} / \mathrm{CIM} / \mathrm{SIG}$

- Possuir todos as suas edificações modeladas em BIM,

- Vincular os dados da Lei Orçamentária Anual (LOA) os códigos dos projetos BIM;

- Fazer gestão da manutenção utilizando softwares BIM;

- Industrializar as suas obras e reformas;

- Possuir todos os seus funcionários da área técnica capacitados na utilização da metodologia BIM;

- Possuir 30\% de seus funcionários com algum tipo de especialização em BIM;

- Eliminar papel na execução das obras;

- Fazer análise de eficiência energética de todas as suas obras;

- Expandir para outras obras a certificação LEED;

- Utilizar o planeamento e gestão de obras com uso do BIM;

- Utilizar os conceitos de Smart Cities (Cidades inteligentes);

- Realizar estudos de mobilidade urbana com software BIM/CIM/SIG; 
- Interligar as informações da prefeitura utilizando software BIM com outros órgãos prestadores de serviço (CASAN, CELESC, Bombeiros, Empresas de telefonia, entre outras);

- Ser o município de referência na adoção do BIM.

\section{Conclusões}

Percebe-se que a implementação da metodologia BIM na Prefeitura de Florianópolis causará grande impacto. Não será uma atividade de curta duração e também não poderá ser encarada como uma ação apenas da gestão atual, mas como um legado para Florianópolis firmar-se como uma das primeiras cidades do Brasil a atender aos requisitos da estratégia BIM BR.

Os resultados serão sentidos pelo corpo técnico, pelas empresas subcontratadas e pela sociedade em geral. Os prazos de execução das obras serão mais assertivos e com obras de melhor qualidade. O impacto ao meio ambiente também será muito importante, pois ao gerar menos desperdício de material e retrabalho, toda a cadeia produtiva ganha. Os órgãos fiscalizadores também poderão se apropriar dos benefícios que a Prefeitura irá colher com a implementação do BIM, pois os dados estarão transparentes e acessíveis.

Entre todos os benefícios que poderão ser colhidos, se adotada a proposta apresentada neste trabalho, o case de sucesso poderá ser replicado para outros municípios e/ou órgãos públicos interessados na adoção do BIM.

Todo esse avanço possibilitará ainda a Prefeitura vislumbrar novos horizontes, como a aprovação de projetos com code checking, possibilitando uma checagem automatizada de projetos, acelerando as aprovações, adotar os conceitos de cidades inteligentes e ainda na adoção de cadastros unificados para melhor gestão do poder público.

A próxima etapa seria buscar a coerência das ações com o que é proposto no Project Management Body of Knowledge (PMBOK), pois é um referencial para excelência no gerenciamento de projetos e de uma adoção de mudança de processos, tanto em órgãos públicos, como em empresas privadas, independente do porte.

O material de referência que norteia implementações da metodologia BIM em órgãos públicos, infelizmente ainda é escasso e requer adaptações, sendo menos conhecido no meio académico, principalmente quando se trata especificamente de implantação no nível municipal. Acreditase que esse trabalho possa estimular outros estudantes a se debruçarem sobre os problemas do ambiente público, que é carente de recursos, sejam financeiros, de mão-de-obra, de conteúdo ou até mesmo de recursos humanos políticos que possam fazer a diferença.

Sendo assim, o objetivo deste trabalho é abrir portas, tanto discussões técnicas, como para discussões políticas, pois o BIM deve ser adotado não apenas como uma política de governo, mas uma política de estado, para que o legado do conhecimento para as próximas gerações não se perca.

\section{Referências}

[1] Chuck Eastman et al. Manual de BIM. Um guia de modelagem da informação da construção para arquitetos, engenheiros, gerentes, construtores e incorporadores. Bookman, 2014 
[2] BRASIL. BIM - Building Information Modelling no Brasil e na união Europeia. Projeto apoio aos diálogos setoriais união europeia - Brasil. Brasília 2015

[3] BRASIL. Decreto 9877 de 22 de Agosto de 2019. Dispõe sobre a Estratégia Nacional de Disseminação do Building Information Modelling e institui o Comitê Gestor da Estratégia do Building Information Modelling. Brasília, 22 de agosto de 2019.

[4] MDIC. Estratégia BIM BR 2018. Site do DNIT Disponível em: http://www.dnit.gov.br/planejamento-e-pesquisa/bim-no-dnit/bim-no-dnit-1/estrategiabim-br Acedido em: 05/10/2019

[5] SANTA CATARINA. Caderno de especificações do Estado de Santa Catarina. Disponível em: http://www.spg.sc.gov.br/visualizar-biblioteca/acoes/comite-de-obras-publicas/427caderno-de-projetos-bim/file Acedido em: 05/06/2019

[6] ABNT ISO NBR 15965 Sistema de classificação da informação da construção - partes 1 a 7

[7] IBGE. Site do IBGE. Disponível https://cidades.ibge.gov.br/brasil/sc/florianopolis/panorama; Acedido em: 05/10/2019

[8] Késia Alves da Silva, Diretrizes para a Prefeitura de Florianópolis - SC atender a estratégia Nacional de disseminação do BIM. Monografia para obtenção do título de Especialista, Universidade Paulista, 2019.

[9] BRASIL. Decreto de 5 de junho de 2017. Institui o Comitê Estratégico de Implementação do Building Information Modelling (CE-BIM). Disponível em: http://www.mdic.gov.br/images/REPOSITORIO/sdci/CGMO/Decreto---ComitEstratgico-BIM_site-Planalto-10.05.2017.pdf

[10] Site G1.com.Prefeitura de Florianópolis utiliza tecnologia pioneira e antecipa entrega de obra em 12 meses; Disponível em: https://g1.globo.com/sc/santa-catarina/especialpublicitario/prefeitura-municipal-de-florianopolis/florianopolis-uma-cidade-paratodos/noticia/2020/02/20/prefeitura-de-florianopolis-utiliza-tecnologia-pioneira-eantecipa-entrega-de-obra-em-12-meses.ghtml. Acedido em 28/02/2020.

[11]Revista TCU (Tribunal de contas da União). Disponível em: https://revista.tcu.gov.br/ojs/index.php/RTCU/article/view/1302/1381; Acedido em: $30 / 07 / 2020$

1302-Texto do artigo-2273-1-10-20160224

[12]BRASIL. Decreto 10.306 de 02 de Abril de 2020. Estabelece a utilização do Building Information Modelling na execução direta ou indireta de obras e serviços de engenharia realizada pelos órgãos e pelas entidades da administração pública federal, no âmbito da Estratégia Nacional de Disseminação do Building Information Modelling Estratégia BIM BR, instituída pelo Decreto nº 9.983, de 22 de agosto de 2019. 